\title{
Investigasi Lift Cylinder Rod Drift Pada Wheel Loader Wa 600-3a
}

\author{
Wahyu Anhar $^{1^{*}, \text { Muhammad Faisal }^{2}}$ \\ ${ }^{1,2}$ Jurusan Teknik Mesin, Politeknik Negeri Balikpapan, Jalan Soekarno-Hatta km. 8, Balikpapan \\ *wahyu.anhar@poltekba.ac.id
}

\begin{abstract}
The productivities of a wheel loader, one of which are determined by performance of hydraulic system. Based on the case study, that was found a problem on wheel loader WA 600-3A Komatsu with serial number 52719. Lift cylinder rod on the unit drifts beyond standard unit limits. This problem occurs in the hour meter (HM) unit of HM 6,398. Measurement of lift cylinder rod motion, visual observation, historical data on periodical service (PS) and trouble, also hydraulic oil analyzer are carried out to determine cause of the damage. Based on measurement results of lift cylinder rod motion, measurement results obtained are $130 \mathrm{~mm} / 15$ minutes. These results indicate that there has been a deviation of motion value of $90 \mathrm{~mm}$ from the standard unit limit. Based on the results of visual observations, wear was found on the inner walls of lift cylinder, wear rings, and piston rings. Furthermore, debris was found on return filter component, and hydraulic oil leakage through head lift cylinder seal. The service life of hydraulic oil based on PS data and trouble unit, known to exceed the life standards of hydraulic oil. Using of hydraulic oil beyond life standard results in a decrease of oil ability to lubricate between sliding components. The internal lift cylinder experiences excessive friction causing wear. As a result of this wear, the lift cylinder rod drifts beyond the standard unit. The presence of debris due to wear and contamination was showed by the analysis of hydraulic oil.
\end{abstract}

Keywords: wheel loader, lift cylinder, drift, wear, hydraulic oil

\begin{abstract}
Abstrak
Produktivitas wheel loader salah satunya ditentukan oleh kinerja sistem hidrolik. Berdasarkan studi kasus terjadi permasalahan pada peralatan kerja wheel loader WA 600-3A Komatsu dengan serial number 52719. Lift cylinder rod pada unit mengalami penurunan (drift) diluar batas standar unit. Permasalahan ini terjadi pada hours meter (HM) unit sebesar HM 6.398. Pengukuran gerak lift cylinder rod, pengamatan visual, data riwayat periodical service (PS) dan trouble, serta hasil analisa oli hidrolik dilakukan untuk menentukan penyebab kerusakan. Berdasarkan hasil pengukuran gerak pada lift cylinder rod bahwa didapatkan hasil ukur sebesar $130 \mathrm{~mm} / 15$ menit. Hasil tersebut menunjukkan bahwa telah terjadi penyimpangan nilai gerak sebesar $90 \mathrm{~mm}$ dari batas standar unit. Berdasarkan hasil pengamatan visual, bahwa ditemukan keausan pada dinding bagian dalam lift cylinder, wear ring, dan piston ring. Selain itu, ditemukan adanya debris pada komponen return filter dan juga terjadi kebocoran oli hidrolik melalui seal head lift cylinder. Masa pakai oli hidrolik berdasarkan data PS dan trouble unit, bahwa diketahui telah melampui standar masa pakai oli hidrolik. Penggunaan oli hidrolik melampaui standar masa pakai menyebabkan turunnya kemampuan oli untuk melumasi diantara komponen yang saling bergesekan. Internal lift cylinder mengalami gesekan berlebih sehingga terjadi keausan. Akibat adanya keausan tersebut, menyebabkan lift cylinder rod mengalami drift diluar standar unit. Adanya debris akibat keausan dan kontaminasi juga telah ditunjukkan oleh hasil analisa oli hidrolik.
\end{abstract}

Kata kunci: wheel loader, lift cylinder, drift, keausan, oli hidrolik 


\section{Pendahuluan}

Artikel ini disusun berdasarkan studi kasus permasalahan yang terjadi pada sistem hidrolik attachment (peralatan kerja) unit wheel loader WA 600-3A Komatsu dengan machine serial number 52719. Permasalahan yang terjadi pada sistem hidrolik tersebut adalah terjadinya penurunan (drift) pada lift cylinder rod diluar standar unit. Hours meter (HM) unit ketika terjadi permasalahan lift cylinder rod drift adalah HM 6.398. Unit wheel loader WA 600-3A yang mengalami lift cylinder rod drift seperti ditunjukkan dalam Gambar 1.

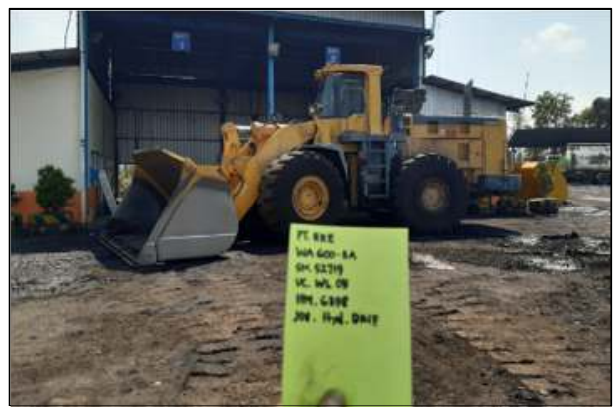

Gambar 1. Unit wheel loader WA 600-3A

Wheel loader merupakan traktor dengan roda karet yang dilengkapi dengan bucket. Wheel loader merupakan traktor serba guna yang banyak digunakan dalam pekerjaan konstruksi, khususnya berkaitan dengan konstruksi infrastruktur [1]. Produktivitas wheel loader, salah satunya dipengaruhi oleh kinerja/kemampuan peralatan kerja yang digerakkan secara hidrolik melalui pergerakan lift cylinder rod.

Sistem hidrolik banyak diterapkan pada alat berat sebagai sumber tenaga penggerak peralatan kerja. Penggunaan hidrolik sebagai sumber tenaga dikarenakan kontrol mudah dan akurat, gaya dan efisiensi tinggi, gaya dan torsi stabil, serta aman dan ekonomis [2]. Dibutuhkan 40\%-60\% dari tenaga engine untuk mengerakkan peralatan kerja wheel loader [3].

Adanya permasalahan pada lift cylinder rod maka proses pengangkatan dan penurunan beban menjadi tidak maksimal. Dalam artian lain pemanfaatan energi menjadi tidak maksimal. Sebaliknya, perkembangan alat berat saat ini sangat berorientasi terhadap efisiensi energi, baik terhadap kerja sistem hidrolik maupun engine sebagai penggerak utama. Sistem hidrolik harus mampu meminimalisir kehilangan tenaga (efisien energi), serta akurat terhadap tekanan dan laju aliran dalam pergerakan actuator (rod cylinder) [4], [5]. Penggunaan fuel pada alat berat, berkaitan dengan tenaga engine yang dihasilkan juga harus efisien, dan rendah emisi $[6,7,8]$. Oleh karena itu, investigasi penyebab penurunan lift cylinder rod akan dibahas dalam artikel ini.

\section{Metoda Penelitian}

Sebelum dilakukan disassembly komponen, maka dilakukan pengukuran gerak turun lift cylinder rod terlebih dahulu. Pengukuran gerak tersebut dilakukan sebagai dasar penentuan apakah lift cylinder rod dalam kondisi normal atau tidak. Metode pengukuran mengacu pada standar pengukuran yang terdapat dalam shop manual WA 600-3A [9]. Pengukuran dilakukan dengan memposisikan unit seperti ditunjukkan dalam Gambar 2. Gerak penurunan lift cylinder rod diukur untuk diketahui nilai aktual, dan selanjutnya dibandingkan dengan nilai standar.

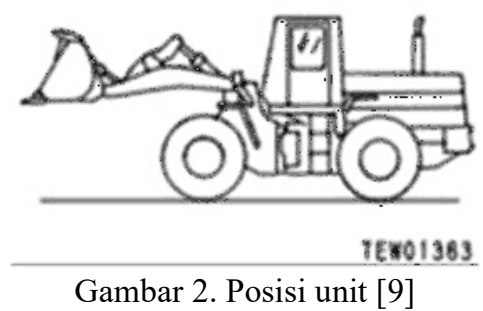

Pengamatan visual juga dilakukan untuk melihat kerusakan yang terjadi pada komponen-komponen lift cylinder rod. Komponen-komponen yang diamati meliputi internal lift cylinder (wear ring, piston ring, dinding dalam cylinder), head cylinder, dan return filter.

Data riwayat periodical service (PS) dan trouble unit juga diperlukan untuk menelusuri kegiatan pemeliharaan dan kondisi unit. Selain 
itu, dokumen hasil analisa oli juga digunakan untuk mengetahui kualitas oli hidrolik.

\section{Hasil Penelitian}

Tabel 1. Hasil ukur gerak lift cylinder rod

\begin{tabular}{cc}
\hline Keterangan & Hasil Pengukuran \\
\hline Standar & $40 \mathrm{~mm} / 15$ menit [9] \\
Aktual & $130 \mathrm{~mm} / 15$ menit \\
\hline
\end{tabular}

Hasil pengukuran gerak lift cylinder rod seperti ditunjukkan dalam Tabel 1. Pengukuran aktual memiliki nilai penurunan sebesar $130 \mathrm{~mm} / 15$ menit. Gambar 3 menunjukkan proses pengukuran di lapangan. Tanda pada posisi A mengalami penurunan hingga ke posisi $\mathrm{B}$, selama 15 menit dengan jarak $130 \mathrm{~mm}$ Terjadi perbedaan dengan nilai standar sebesar $90 \mathrm{~mm}$. Adanya perbedaan ini menunjukkan bahwa lift cylinder rod mengalami permasalahan.

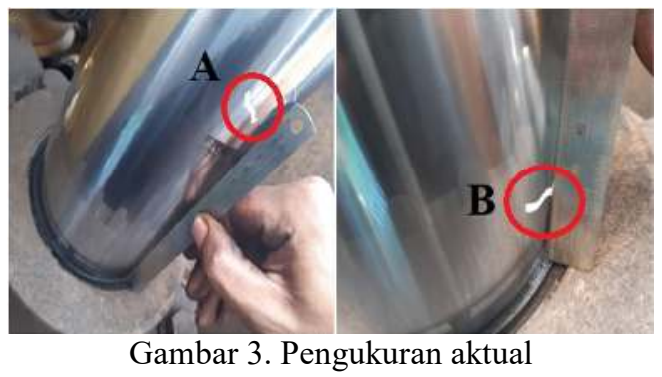

Gambar 4 merupakan hasil pengamatan visual yang menujukkan kondisi internal lift cylinder. Terlihat bahwa bagian wear ring, piston ring dan dinding dalam cylinder terdapat goresan-goresan dalam. Adanya goresan-goresan dalam menunjukkan bahwa bagian internal lift cylinder mengalami keausan.

Terjadi ketidaknormalan dalam pergerakan lift cylinder rod terhadap dinding dalam silinder. Secara normal, gerakan sliding lift cylinder rod terhadap dinding dalam silinder tidak akan menyebabkan keausan. Bagian dalam lift cylinder terdapat oli hidrolik yang berfungsi sebagai pelumas terhadap komponen-komponen yang saling bergesekan.

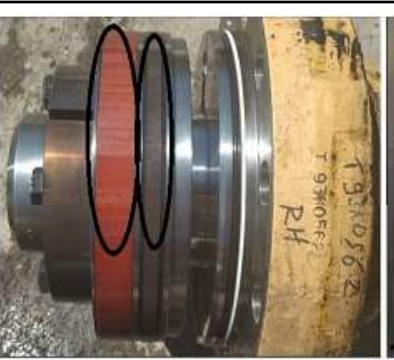

(a) (a) wear ring dan piston ring

(b) dinding dalam lift cylinder

Gambar 4. Kondisi internal lift cylinder

Tabel 2. PS dan trouble unit [10]

\begin{tabular}{|cccc}
\hline No. & Breakdown & HM & Keterangan \\
\hline 1. & $14 / 09 / 2018$ & 279 & PS 250 \\
2. & $27 / 09 / 2018$ & 521 & PS 500 \\
3. & $23 / 10 / 2018$ & 1.018 & PS 1000 \\
4. & $07 / 11 / 2018$ & 1.281 & PS 250 \\
5. & $05 / 01 / 2019$ & 2.101 & PS 250 \\
6. & $29 / 01 / 2019$ & 2.521 & PS 2000 \\
7. & $11 / 02 / 2019$ & 2.744 & PS 250 \\
8. & $27 / 02 / 2019$ & 3.018 & PM 1000 \\
& & & Trouble lift cylinder drift (flushing \\
9. & $01 / 03 / 2019$ & 3.055 & hydraulic tank, change oil \\
& & & hydraulic) \\
10. & $01 / 06 / 2019$ & 4.002 & PS 4000 (No change oil hydraulic) \\
11. & $22 / 06 / 2019$ & 4.249 & PS 250 \\
12. & $23 / 07 / 2019$ & 4.745 & PS 250 \\
13. & $08 / 08 / 2019$ & 5.011 & PS 1000 \\
14. & - & 5.055 & No change oil hydraulic \\
15. & $24 / 08 / 2019$ & 5.251 & PS 250 \\
16. & $10 / 09 / 2019$ & 5.525 & PS 500 \\
17. & $21 / 10 / 2019$ & 6.038 & PS 2000 \\
18. & $16 / 11 / 2019$ & 6.398 & Trouble lift cylinder drift \\
\hline
\end{tabular}

Data riwayat PS dan trouble unit wheel loader WA 600-3A dengan machine serial number 52719 [10], seperti ditunjukkan dalam Tabel 2. Berdasarkan data riwayat PS dan trouble unit dapat diketahui interval pergantian oli hidrolik. Berdasarkan Operation and Maintenance Manual (OMM) WA 600-3A, bahwa pergantian oli hidrolik unit dilakukan setiap PS 2.000 (interval masa pakai oli hidrolik 2.000 jam) [11]. Berdasarkan aktivitas nomor 6 bahwa PS 2.000 dilaksanakan pada HM 2.521. Pergantian oli hidrolik telah mengalami keterlambatan sebesar 521 jam pemakaian. Aktivitas nomor 9 (HM 3.055) menunjukkan bahwa terjadi lift cylinder rod drift. Dalam masa pakai tersebut komponen masih dalam garansi sehingga dilakukan pergantian lift cylinder assy. Selain itu, dilakukan flushing hydraulic tank dan pergantian oli hidrolik. Masa pakai oli hidrolik 
dihitung menjadi nol jam pemakaian. Aktivitas nomor 10 dilakukan PS 2.000 tanpa pergantian oli hidrolik karena masa pakai masih 947 jam sejak aktivitas nomor 9. Pergantian oli hidrolik seharusnya dilaksanakan pada HM 5.055, tetapi aktivitas ini tidak dilakukan. Pergantian oli hidrolik baru dilakukan pada HM 6.038 bersamaan dengan PS 2.000. Hal ini mengakibatkan pergantian oli hidrolik kembali mengalami keterlambatan karena masa pakai menjadi 2.983 jam sejak aktivitas nomor 9 (terlewat 983 jam pemakaian). Aktivitas 18 (HM 6.398) unit kembali mengalami lift cylinder rod drift.

Berdasarkan riwayat PS dan trouble unit tersebut bahwa terjadi 2 kali permasalahan lift cylinder rod drift. Permasalahan tersebut diawali dengan keterlambatan dalam melakukan pergantian oli hidrolik. Masa pakai oli hidrolik yang melewati standar masa pakai akan berakibat menurunnya kualitas oli hidrolik, khususnya berkaitan dengan kemampuan pelumasan. Pelumas (oli hidrolik) berfungsi untuk mengurangi gesekan dan keausan, membuang panas, serta mengalirkan debris (pembersih) pada bagian-bagian yang saling gerak meluncur (sliding) [12]. Hal ini bersesuaian dengan hasil pengamatan visual internal lift cylinder yang mengalami keausan. Gesekan antar komponen internal lift cylinder menjadi berlebih karena tidak maksimalnya pelumasan. Kegiatan perawatan berkala (PS) memegang peranan penting dalam menjaga kinerja unit khususnya sistem hidrolik dan oli hidrolik. Lebih dari 50\% permasalahan sistem hidrolik berkaitan dengan oli hidrolik [13].

Pola keausan yang terjadi pada internal lift cylinder berupa goresan-goresan dalam. Pola keausan berupa goresan (wedge formation) menunjukkan bahwa keausan yang terjadi adalah keausan abrasi [12]. Dampak gesekan berlebih yang terjadi pada internal lift cylinder mengakibatkan permukaan bagian internal lift cylinder lepas menjadi debris. Bersirkulasinya oli hidrolik menjadikan debris tersebut juga ikut bersikulasi. Terlihat dalam Gambar 5 bahwa terdapat debris di sekitar return filter. Fungsi return filter adalah untuk menyaring kotoran oli hidrolik setelah bersirkulasi dari sistem (cylinder) sebelum mengalir kembali ke tanki. Adanya debris ini menunjukkan bahwa keausan abrasi diawali dengan keausan abrasi-two body hingga akhirnya terjadi keausan abrasi-three body.

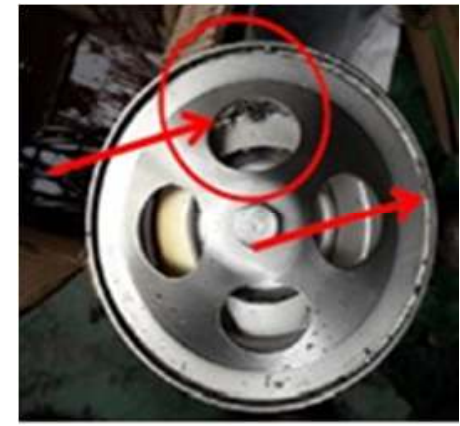

Gambar 5. Kondisi return filter

Berdasarkan pengamatan visual lainnya bahwa terjadi kebocoran oli hidrolik pada head lift cylinder seperti ditunjukkan dalam Gambar 6. Kebocoran oli hidrolik ini disebabkan seal pada head lift cylinder mengalami penurunan kualitas (elastisitas). Terjadi gesekan berlebih antara cylinder rod terhadap seal karena penurunan kualitas oli hidrolik. Selain itu, faktor adanya debris di dalam cylinder menyebabkan ikut bergesekan antara rod dengan seal. Terjadinya keausan di seal menyebabkan kebocoran oli hidrolik pada cylinder.

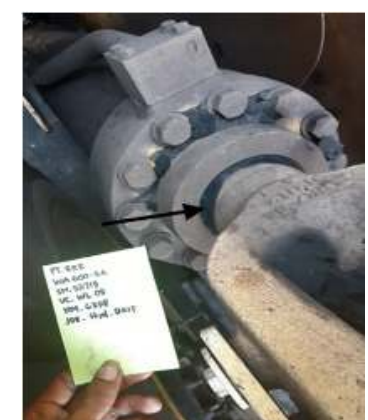

Gambar 6. Kebocoran oli hidrolik

Berkaitan dengan hasil analisa oli hidrolik [14] dimulai sejak tanggal 01 Juni 2019 hingga 21 Oktober 2019, terjadi penambahan kontaminasi. Tabel 3 menujukkan beberapa hasil analisa oli hidrolik wheel loader WA 600-3A dengan machine 
serial number 52719. Terjadi penambahan unsur $\mathrm{Fe}, \mathrm{Cu}$ dan $\mathrm{Si}$ pada oli hidrolik. Unsur $\mathrm{Fe}$ dan $\mathrm{Cu}$ merupakan unsur dari internal cylinder. Hasil ini menunjukkan bahwa komponen internal cylinder telah terjadi pengikisan (keausan). Terdapatnya unsur Si menunjukkan bahwa kontaminan/pengotor (debu) yang berasal dari luar sistem telah masuk kedalam sistem. Masuknya kontaminan tersebut melalui seal head lift cylinder. Adanya kebocoran oli melalui seal head lift cylinder (Gambar 6) menunjukkan bahwa seal tidak maksimal membatasi/sekat antara bagian luar dengan bagian dalam sistem.

Tabel 3. Hasil analisa oli hidrolik [14]

\begin{tabular}{|c|c|c|c|}
\hline \multirow{2}{*}{ Sample date } & \multicolumn{2}{|c|}{ Wear metal } & Contaminant \\
\hline & $\mathbf{F e}$ & $\mathbf{C u}$ & $\mathbf{S i}$ \\
\hline $21 / 10 / 2019$ & 16 & 14 & 5 \\
\hline 10/9/2019 & 8 & 13 & 3 \\
\hline 8/8/2019 & 6 & 10 & 3 \\
\hline $1 / 6 / 2019$ & 4 & 12 & 2 \\
\hline
\end{tabular}

\section{Kesimpulan}

Telah terjadi permasalahan pada unit wheel loader WA 600-3A Komatsu dengan machine serial number 52719 berupa lift cylinder rod drift. Penyebab utama terjadinya lift cylinder rod drift adalah keausan internal komponen lift cylinder yang disebabkan penurunan kualitas oli hidrolik. Kegiatan perawatan berkala unit (PS), khususnya berkaitan dengan masa pergantian oli hidrolik memegang peranan penting terhadap life time komponen sistem hidrolik

\section{Saran}

Variabel-variabel dalam kegiatan perawatan berkala unit (PS) harus dilaksanakan secara menyeluruh, dan terkontrol dengan baik. Penelitian lebih lanjut dapat dilakukan terkait tindakan dalam aktivitas perawatan untuk mengetahui apakah terjadi penyimpangan atau tidak, variabel penyebab jika terjadi penyimpangan, dan proses kontrol kegiatan.

\section{Daftar Pustaka}

[1] Y. You, D. Sun dan D. Qin, "Shift strategy of a new continuously variable transmission based wheel loader," Mechanism and Machine Theory, vol. 130, p. 313-329, 2018.

[2] R. Doddannavar, A. Barnard and S. Mackay, "Applications of hydraulic systems," in Practical Hydraulic, 2015, pp. 175-180.

[3] Y. Kan, D. Sun, Y. Luo, K. Ma and J. Shi, "Optimal design of power matching for wheel loader based on power reflux hydraulic transmission system," Mechanism and Machine Theory, vol. 137, p. 67-82, 2019.

[4] T. Koitto, H. Kauranne, O. Calonius, T. Minav and M. Pietola, "Experimental Study on Fast and Energy-Efficient Direct Driven Hydraulic Actuator Unit," Energies, vol. 12, no. 1538, pp. 1-17, 2019.

[5] S. Ketelsen, D. Padovani, T. O. Andersen, M. K. Ebbesen and L. Schmidt, "Classification and Review of Pump-Controlled Differential Cylinder Drives," Energies, vol. 12, no. 1293, pp. 1-27, 2019.

[6] L. Tianliang and W. Qingfeng, "Hydraulic accumulator-motor-generator energy regeneration system for a hybrid hydraulic excavator," Chinese Journal of Mechanical Engineering, vol. 25, no. 6, pp. 1121-1129, 2012.

[7] W. Zhang, J. Wang, S. Du, H. Ma, W. Zhao and H. Li, "Energy Management Strategies for Hybrid Construction Machinery: Evolution, Classification, Comparison and Future Trends," Energies, vol. 12, no. 2024, pp. 1-26, 2019.

[8] J. Li, J. Zhao and X. Zhang, "A Novel Energy Recovery System Integrating Flywheel and Flow Regeneration for a Hydraulic Excavator Boom System," Energies, vol. 13, no. 315, pp. 1-25, 2020.

[9] Komatsu, Shop Manual Wheel Loader WA 600-3A, Japan: Komatsu, 2005.

[10] PT. Bhumi Rantau Energi, Historical Service, Banjarmasin, 2019.

[11] Komatsu, Operation and Maintenance Manual Wheel Loader WA 600-3A, Japan: Komatsu, 2006.

[12] ASM International, "Friction, Lubrication, and Wear Technology," in ASM Handbook, vol. 18, ASM International, 1992, pp. 123, 
337.

[13] R. Doddannavar, A. Barnard and S. Mackay, "Maintenance and troubleshooting," in Practical Hydraulic Systems, 2015, pp. 190207.
[14] PT. Bhumi Rantau Energi, Scheduled Oil Sampling Report, Banjarmasin, 2019. 